\title{
Design and Implementation of Mathematical Model for Revenue Management in Hospitality Industry
}

\section{Ebiendele E Peter ${ }^{1 *}$ and Ebiendele Helen ${ }^{2}$}

${ }^{1}$ Department of Basic Science, School of General Studies, Auchi Polytechnic, Nigeria

${ }^{2}$ National Institute for Hospitality and Tourism, Nigeria

\begin{abstract}
Revenue management is the art and science of maximizing revenue under various variable conditions. It is a management tool that has the objective of increasing sale revenues by manipulating the prices at which fixed products in the hotels are made available for sale in relation to the current and forecasted demand. This paper focus on the design and implementation of mathematical model, of the type of linear programming, which will help the revenue managers in the hospitality industry to manage their revenue to enable the hotel's maximized their contributions. This model becomes necessary today in the hospitality industry, because of the complex decisions facing the hotel's manager as regarding what product to produce, quantity of the product and services to produce such product and so on. How this model could be applied in the food and beverages department in the hospitality industry was demonstrated. The paper also illustrated the skill of who is to be a revenue manager in the hospitality sector. The paper concludes and recommends that if the model is adopted, it will improve the sector revenue generation among others and reduce wastage, if not totally eliminated in the foods and beverages departments.
\end{abstract}

Keywords: Design and implementation; Revenue management; Hospitality industry

\section{Introduction}

Revenue management (RM) is the art and science of maximizing revenue under variable conditions. It is a management tool that has the objective of increasing sales revenues by manipulating the prices at which fixed products (that is, hotel produces and airline seats etc.) are made available for sale in relation to the current and forecasted demand. As revenue management has developed, it has becomes more disciplined and technical in using a variety of analytics to predict consumer demand, and to optimize the inventory and price availability to maximize revenue. The essence of this discipline is in understanding the customer's perception of product valued and accurately aligning product prices, placement and availability with each customer segment. Most hospitality industries are face with complex decisions regarding their pricing and selling strategy namely, what product to sell, who is the target customer, quantity to product, when is the ideal time to sell, how much to sell that product for, and what is the "best" route to market the product (considering such factors as cost of production, cost of sale and brand image).

As a result, the concept of revenue management can be applied to the selling of hotel bedrooms and other areas in hospitality industry such as conference, food and beverage where the management of fixed resources is essential to maximize profit. Revenue management relies on the collection of data and factual evidence to support strategies and their tactical application, to increase both revenue and profit. Revenue management relies on the collection of data and factual evidence to support strategies and their tactical application, to increase both revenue and profit. Revenue management uses the basic principles of supply and demand economics, in a tactical way, to generate incremental revenues.

\section{Objective of the Paper}

The paper focus on the design and implementation of mathematical model of the type linear programming that we help the managers of hospitality industry in Nigeria particularly in the food and beverage department in managing their revenues to enable them maximized the organization profits, and the paper also give details of the skills required for a hotel revenue manager.

\section{Skills required for a revenue manager}

A successful revenue manager must be a well-rounded individual, with multiple skills. Typically, the core skills are perceived to be:

- Attention to detail

- Numerical skills

- Computer literate

- Strong excel capabilities

- Understanding of distribution channels

- Ability to make decision from multiple data sources

- Ability to work under pressure in changing environment.

In addition, the following traits and capabilities are also new essential for a successful RM manager.

\section{Relationship skills}

The most effective revenue managers spend a considerable amount of their time managing people and building relationships - almost as much as they do managing revenue.

\section{Creative thinking}

Effective revenue managers are long term strategists and often

*Corresponding author: Ebiendele E Peter, Department of Basic Science, School of General Studies, Auchi Polytechnic, Nigeria, Tel: +2348069035625 E-mail: peter.ebiendele@yahoo.com

Received February 21, 2018; Accepted April 03, 2018; Published May 10, 2018

Citation: Peter EE, Helen E (2018) Design and Implementation of Mathematical Model for Revenue Management in Hospitality Industry. J Hotel Bus Manage 7: 175. doi: 10.4172/2169-0286.1000175

Copyright: (๑) 2018 Peter EE, et al. This is an open-access article distributed under the terms of the Creative Commons Attribution License, which permits unrestricted use, distribution, and reproduction in any medium, provided the original author and source are credited. 
responsible for corporate change. Therefore, they rely on innovative thinking to develop and implement new ideas.

\section{Effective sales ability}

Revenue managers inevitably spend a part of their day "selling" rate and yield recommendations to their colleagues who will need to adopt their pricing strategies before they can have an impact.

\section{On-property experience}

It is beneficial to have on-property background and understand the impacts of RM decisions at a hotel level, with a consideration for all operating areas.

\section{Training ability}

Because of high property turnover, good training and development skills are critical to the successful implementation of revenue management.

\section{Recommendations}

If hotel teams do not understand the sectors that go into recommendations, they may disregard the pricing, yield and distribution guidelines and therefore fail to optimize revenue opportunities.

\section{Strong communication skills}

Good revenue managers need to be excellent communicators (and listeners) who are as effective at presenting their ideas as they are at using a computer.

\section{Technically confident}

Revenue managers need to embrace current technology and distribution techniques, to ensure these systems are profit enhancing and not lab our consuming. The Revenue Manager should be an integral part of the decision-making process in a hotel and provide direction and strategy based on facts, data and analysis. The revenue manager should have expertise in managing the various systems (Central Reservation System, Property Management Systems, Revenue Management Systems e.t.c) and be capable of synthesizing data making sound business decisions to positively affect results.

\section{Literature Review}

\section{Overview of review management}

The deregulation of the airline industry is generally seen as the catalyst for revenue management (and it precursor, yield management). The terms revenue management and yield management are often confused, yet there is a key distinction between the two disciplines, whereas revenue management involves predicting consumer behavior by; segmenting markets, forecasting demand and optimizing prices for several different types of products, yield management refers specifically to maximizing revenue through inventory control, thus yield management is a tactical application within the broader field of "revenue management". After the US government deregulated the airline industry in the early 1980s, revenue management practices were first launched. Over the next few years, yield tactics became common practice among major airline. However, revenue management may reasonably be assigned an inception early 1985 when American airlines launched its "ultimate super saver" fares to complete with the low cost carrier people express. Revenue management was born out of the need to fill at least a minimum number of seats to covered; the remaining capacity could then be sold at higher rates to maximize revenue and profit. The hotel industry recognized the benefits of adopting a revenue management approach as practiced by the airline sector but initially growth of the technique was held back by the lack of appropriate technology available to manage data and the shortage of meaningful information about guests. The challenge to overcome by the hotels was how to manage the length of stay-a feature which is different to that experienced by the airlines. assert that, given some revenue streams such as restaurants, which have high variable cost associated with them, for one, has called for a shift in focus from revenue to profitability, further suggested that, the future will require revenue manager to consider both the revenue and costs associate with others revenue stream as it expands its focus beyond the management of rooms' revenue to a more complete profit-based approach.

Cross was on the opinion of the ability to understand total customer contribution overtime and to optimize price and inventory availability for customers based on estimate of their longer term profit potential have been recognized as a future milestone for revenue manager [1]. The focus of the hospitality industry is on successful operation mechanism to optimize their efficiency, which we results to achieve profitability. Successful operation of revenue management technique we help both small and big hotels to realized and maximized their profits. Operations of revenue technique in the hospitality sectors, we help to identify the needs of their customers, also having the right quality and quantity of products and services and also setting up the optimal prices to be offered to their customers. Esse suggested that revenue management we provide more benefits to customers and this will lead to greater performance results. In its essence, Cross conclude that revenue management encompasses activities that concentrate on proper allocation of resources by virtue of which better profits can be achieved $[2,3]$.

Hospitality sectors today have stands out to be one of the organization that have witnessed utilization of revenue management technique. Chiang further stated that hotel industry is among the major areas of revenue management application, as hotel's products are perishable, hotel's fixed costs are higher than the variable costs, and the demand varies over time [4]. While also add that maximizing revenue is important for hotels because of their high fixed costs and their fixed capacity" [5]. It is obvious from the about author's contribution of the importance of revenue management in hospitality industry, it's considered today (revenue management) we enhance operational success in hospitality sectors in Nigeria. Chiang further assert that, there are several different areas of revenue management, like, pricing, capacity control, overbooking and so on, that they are all highly connected and needs to be considered jointly [4]. Sheryl and Kimes were on the opinion that the use of linear programming which are defined as a precise rule, or set of rules specifying how to solve a problem, can be a very effective way for business owners to accurately conduct calculations, process data and gather important information about the buying habits of consumers [6]. Cross further assert that researchers have suggested that revenue management should be applied also to non-room revenue sources, that the industry (Hostel's) is now moving toward extending the scope of revenue management practice beyond the rooms division [3]. O conner stated that, given that some revenue streams such as restaurants have high variable fixed cost associated with them [7]. Cross were on the viewed that traditional hotel revenue management is in transition from being chiefly a standalone, tactical technique for managing rooms inventory to adopting a strategic, customer-centre approach to demand creation and profit [3] 


\section{Design and Implementation of Mathematical Model}

Linear programming deals with the optimization of a function of variables known as objective function, subject to set of linear equalities/ inequalities known as constraints. The constraints may be imposed by different sources such as market demand, production processes and equipment, storage capacity, raw material availability etc. By linearity is meant a mathematical expression in which the variables have unit power only.

Linear programming (LP) is used for optimization problems that satisfy the following conditions:

1. There is a well-defined objective function to be optimized and which can be expressed as a linear function of decision variables.

2. There are constraints on the attainment of the objective and they are capable of being expressed as linear equalities/ inequalities in terms of variables.

3. There are alternative courses of action.

4. The decision variables are interrelated and non-negative.

5. Resources are in limited supply.

\section{Method of solving linear programming (LP) problems}

1. Graphical method

2. Simplex tableau method

3. Algebraic method.

In this paper, graphical method will be demonstrated. A linear programming problem with only two variables presents is a simple case of graphical method.

A. Represents the given problem in mathematical form, i.e. formulate an (LP) model for the given problem.

B. Represents the given constraints as equalities on $x_{1}, x_{2}$ coordinates plane and find the convex region formed by them.

C. Plot the objective function.

D. Find the vertices of the convex region. The vertex that gives the optimal solution to the problem.

Linear programming problem may have the following characteristic:

i. A definite and unique optimal solution

ii. An infinite number of optimal solution

iii. An unbounded solution and

iv. No solution.

But when the problem involves more than two variables, simplex tableau method, and with the help of recent technological development, MATLAB (R 2009a-32 bit) are good tools to solve such linear programming (LP) problems.

\section{Model representations}

Objective functions is to (maximize or minimize) the contribution.

$$
\mathrm{Z}=\mathrm{C}_{1} \mathrm{X}_{1}+\mathrm{C}_{2} \mathrm{X}_{2}-\cdots-\cdot-\mathrm{C}_{\mathrm{n}} \mathrm{X}_{\mathrm{n}}
$$

Non-Negative linear constraints

$$
\begin{aligned}
& a_{11} X_{1}+a_{12} X_{2},+-----,+a_{1 n} X_{n}(\leq \text { or } \geq) b_{1} \\
& a_{21} X_{22} X_{2}+,------,+a_{2 n} X_{n}(\leq \text { or } \geq) b_{2} \\
& a_{m 1} X_{1}+a_{m 2} X_{2}+-------, a_{m n} X_{n}(\leq \text { or } \geq) b_{n}
\end{aligned}
$$

\section{Case 1}

As the Hotel Manager of John's hotel Ltd, that sells two types of donuts: Regular and chocolate. The contribution for regular and chocolate are 4.00 and 5.00 respectively. The products are produced in three operations. $\mathrm{A}, \mathrm{B}$, and $\mathrm{C}$ (Table 1).

Assuming that the time available can be allocated to either type of the products.

Require:

A. Formulate the linear programming model for this problem,

B. Which of the production operations (A, B and C) we maximizes the Hotel profits,

C. How much slack time is available for each operation?

Step 1: Key decision is to determine the extent production operations (A, B and C) that we maximize the hotel profits.

Step 2: let these extents be $\mathrm{x}$ and $\mathrm{y}$ respectively.

Step 3: feasible alternatives are sets of values of $x, y$ where $x \geq 0$ and $\mathrm{y} \geq 0$.

Step 4: objectives are to maximize $Z=4 x+5 y$.

Step 5: constraints are on the time available for operations A, B and $\mathrm{C}$.

For operation $\mathrm{A}, \mathrm{x}+2 \mathrm{y} \leq 700$.

For operation $B, 5 x+4 y \leq 1700$.

For operation $C, 3 \mathrm{x}+2 \mathrm{y} \leq 850$.

Solution: Now convert the inequality to equation, to have:

$x+2 y=700$

$5 \mathrm{x}+4 \mathrm{y}=1700$

$3 \mathrm{x}+2 \mathrm{y}=850$

For us to be able to draw the graphs, we need co-ordinate points. Thus, we have to assume that the unknown variables $(\mathrm{x}, \mathrm{y})$ equals zero after the other. That is form equation (1), Assume $\mathrm{x}=0$, we have:

$0+2 y=700, y=700 / 2 \equiv 350$

Same eqn. (1), assume $y=0$, to have;

$\mathrm{X}+2(0)=700, \mathrm{x}=700$.

Therefore equation (1) co-ordinate points are:

$\left|\begin{array}{cc}x & y \\ 0 & 350 \\ 700 & 0\end{array}\right|$

\begin{tabular}{|l|c|c|c|}
\hline & A & B & C \\
\hline Regular (R) & 1 & 5 & 3 \\
\hline Chocolate (C) & 2 & 4 & 2 \\
\hline Maximum time available secondly & 700 & 1700 & 850 \\
\hline
\end{tabular}

Table 1: The above are the time required for each products. 
For equation (ii) when $\mathrm{x}=0$, we have:

$5(0)+4 y=1700, y=1700 / 4=425$.

Also when $\mathrm{y}=0,5 \mathrm{x}+4(0)=1700, \mathrm{x}=1700 / 5=340$.

The co-ordinate points for eqn. (2) is given as:

$$
\left|\begin{array}{cc}
x & y \\
0 & 425 \\
340 & 0
\end{array}\right|
$$

From eqn. (3):

Assume $\mathrm{y}=0$

$3 \mathrm{x}+2(0)=850, \mathrm{x}=850 / 3=283.3$.

Also when $\mathrm{x}=0$, we have $3(0)+2 \mathrm{y}=850$

$\mathrm{Y}=850 / 2=425$.

Therefore, the co-ordinate points for eqn. (3) are given below:

$$
\left|\begin{array}{cc}
x & y \\
0 & 425 \\
285 & 0
\end{array}\right|
$$

The shaded area is the feasible solution region (Figure 1). We can also solve the equations simultaneously to find the third corner points. The equations with the third corner point's area:

$3 x+2 y=850$

$\mathrm{X}+2 \mathrm{y}=700$

Subtract equation (1) from (2)

$2 \mathrm{x}=150$

$\mathrm{x}=75$.

And substitute $\mathrm{x}=75$ in equation (1)

$2 \mathrm{y}=700-75$

$y=312.5$.

We can now substitute the corner points into the functions.

$1^{\text {st }}=(0,350)$

$2^{\text {nd }}=(283.3,0)$

$3^{\mathrm{rd}}=(75,312.5)$

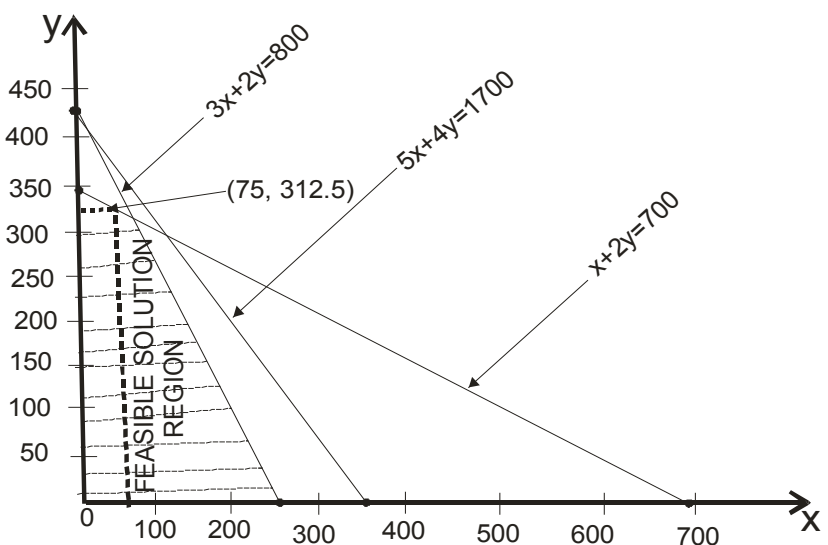

Figure 1: The coordinate points given above can be represented graphically.
Our objective function is $4 \mathrm{x}+5 \mathrm{y}$

For the $1^{\text {st }}$ corner point

$4(0)+5(350)=1750$

$2^{\text {nd }}$ corner point

$4(283.3)+5(0)=1133.2$

$3^{\text {rd }}$ corner point

$4(288.3)+5(312.5)=1862.5$

Therefore, the production operations that we maximizes contribution is

$x=75, y=312.5$

And the amount is 1862.5

Calculating the slack time

Using the optimum production operations

$\mathrm{x}=75, \mathrm{y}=312.5$

$\mathrm{x}+2 \mathrm{y}=75+2(312.5)=700$

Time available $=700$ slack time $=(700-700)=0$

For operation B

$5 x+4 y=5(75)+4(312.5)=1625$

Time available $=1700$ therefore slack time $1700-1625=75$ mins.

For operation C

$3 x+2 y=3(75)+2(312.5)=850$

Time available $=850$

Therefore, slack time $=(850-850)=0$.

\section{Case 2}

AJET Hotel ltd manufacturer two products $\mathrm{A}$ and $\mathrm{B}$ on which the profits earned per unit are $\$ 3$ and $\$ 4$ respectively. Each product is processed on two machines $\mathrm{M}_{1}$ and $\mathrm{M}_{2}$. Product A require one minute of processing time on $M_{1}$ and two minutes on $M_{2}$, while $B$ requires one minute on $M_{1}$ and one minute on $M_{2}$. Machine $M_{1}$ is available for not more than 7 hrs. 30 mines. While machine $M_{2}$ is available for not more than $10 \mathrm{hrs}$ during working day. Require to find which of the products $A$ and $B$ to be manufactured to maximum the Hotel profit.

Formulation of the model, Same as given in case I. Follow the five (5) steps before solution.

Another method shall be use to solve this problem.

Method 2: The two constraints are $x_{1}+x_{2} \leq 450$ and $2 x_{1}+x_{2} \leq 600$. We plot line $\mathrm{x}_{1}+\mathrm{x}_{2}=450$, by joining two convenient points, say $(0,450)$ and $(450,0)$ and line $2 x_{1}+x_{2}=600$ by joining points, say $(0,600)$ and $(300,0)$. The corner points, $\mathrm{C}(0,450) \mathrm{D}(150,300)$ and $\mathrm{E},(300,0)$. Values of the objective function

$$
\begin{aligned}
& Z=3 x_{1}+4 x_{2} \\
& Z(C)=1,800, Z(D)=450+1200=1650 \\
& Z(E)=900
\end{aligned}
$$

Thus the maximum value of $Z$ is 11,800 and it occurs at the vertex C $(0,450)$. 
Citation: Peter EE, Helen E (2018) Design and Implementation of Mathematical Model for Revenue Management in Hospitality Industry. J Hotel Bus Manage 7: 175. doi: 10.4172/2169-0286.1000175

Page 5 of 5

Hence the solution to the problem is

$\mathrm{x}_{1}=0, \mathrm{x}_{2}=450$ and $\mathrm{Z}_{\text {max }}=\mathrm{N} 1,800$

i.e the firm will maximized profits in product $\mathrm{B}$.

\section{Conclusion and Recommendation}

The paper was on the design and implementation of mathematical model of the type linear programming for revenue management in Nigeria Hospitality sectors. The paper also gives details of the core skills of who to be a revenue manager in Hospitality sector. How the model could be use in food and beverages departments to maximize the Hotel profits was also demonstrated. It was observed in case I, the products in operations $\mathrm{A}$ and $\mathrm{C}$ we maximized the hotel contributions, and for case II, product B we maximized the hotel profits. It was recommends that if the model is adopted, it will not only increases the sector revenue generation, but we also reduce wastage, if not totally eliminated in the foods and beverages departments.

\section{References}

1. Cross RG, Higbie JA, Cross ZN (2011) Milestones in the application of analytical pricing and revenue management. Journal of Revenue and Pricing Management 10: 8-18.

2. Esse $T$ (2003) Securing the value of customer value management. Journal of Revenue and Pricing Management 2: 166-171.

3. Cross RG, Higbie JA, Cross DG (2009) Revenue management's renaissance: A rebirth of the art and science of profitable revenue generation. Cornell Hospitality Quarterly 50: 58-81.

4. Chiang WC, Chen JC, Xiaojing X (2007) An overview of research on revenue management: current issues and future research. International Journal of Revenue Management.

5. Thompson G (2010) Restaurant Profitability Management: The evolution of restaurant revenue management. Cornell Hospitality Quarterly 51: 308-322.

6. Kimes SE (2017) The Future of Hotel Revenue Management. Cornell Hospitality Report. Cornell University Centre for Hospitality Research 17: 3-10.

7. O'conner P, Murphy J (2008) Hotel yield management practices across multiple electronic distribution channels: Information Technology and Tourism 10: 161-172. 